\title{
Magnesium pemoline: Effect on acquisition and retention of discriminated avoidance behavior
}

\author{
YASUKO FILBY ${ }^{l}$, S. SZARA AND B. SALZMAN \\ CLINICAL NEUROPHARMACOLOGY RESEARCH CENTER, NIMH, ST. ELIZABETHS HOSPITAL, WASHINGTON, D. C.
}

Recently, Plotnikoff suggested that magnesium pemoline, a mild CNS-stimulant, enhanced learning and memory in rats whereas other CNS-stimulants did not. We compared magnesium pemoline with another CNS-stimulant, d-amphetamine, and a placebo, in a bar-press avoidance situation. Both drug groups showed faster acquisition than the placebo; the magnesium pemoline group, in addition, showed less intertrial responding than the d-amphetamine group. Magnesium pemoline appears to enhance avoidance performance by increasing the rats' responsivity to the warning signal. There was no enhanced retention due to the drug.

Plotnikoff (1966) found that magnesium pemoline (MgPe) given orally to rats significantly enhanced the acquisition and retention of avoidance learning in a jump-out apparatus. Both methamphetamine and methylphenidate, however, were not effective. A separate study (Glasky \& Simon, 1966) found that MgPe increased RNA synthesis, while methamphetamine and methylphenidate, among other CNS stimulants also tested, did not. 2 Thus, the two experiments in conjunction suggested that MgPe enhanced learning and memory by stimulating RNA synthesis.

The present study was designed to test in another avoidance situation the generality and reliability of the effects of $\mathrm{MgPe}$ observed by Plotnikoff. In the present study, the avoidance response was a bar press instead of a leap out of the apparatus as in Plotnikoff's study, and $\mathrm{Ss}$ were run in $1-\mathrm{h}$ sessions (a single session having approximately 100 trials) until a predetermined level of acquisition performance was met (Instead of the fixed number of only 10 trials given in Plotnikoff's acquisition stage). Thus, all Ss were taken to a uniform level of acquisition performance before retention testing in contrast to the variable levels of acquisition performance in Plotnikoff's study. In addition, retention testing was conducted following a 30-day rest interval after the last acquisition session, rather than the single-day interval allowed by Plotnikoff.

Subjects

Eighteen male Osborn-Mendel albino rats were randomly assigned to one of three groups, the MgPe group, the d-amphetamine (d-a) group, and the placebo (P) group. All Ss were 120 days old at the start of the study and were on ad lib food and water throughout.

Apparafus

A standard, commercially available rat chamber (Foringer Model No. 1107) equipped with a single bar, and a grid floor connected to a Foringer shock scrambler and shock source, were used. Programming and recording equipment were housed in an adjacent room.

\section{Procedure}

Each $S$ was given an IP injection of his designated drug $30 \mathrm{~min}$ before each session. The drug dosages were $40 \mathrm{mg} / \mathrm{kg}$ for the MgPe group, and $3 \mathrm{mg} / \mathrm{kg}$ for the d-a group. 3 One hour sessions were given every other day for five weeks, then daily. During a session, a 10-sec warning signal sounded at irregular intervals (the average time between signals being approximately $35 \mathrm{sec}$ ). If the animal did not bar press during the 10-sec buzzer, he was given a 1-sec inescapable shock of approximately $.7 \mathrm{~mA}$. A bar press during buzzer onset immediately terminated the buzzer and prevented the shock. A bar press in the absence of the buzzer had no effect; it neither postponed buzzer nor shock onset. Ss were trained until they met a criterion of seven consecutive sessions at above $65 \%$ successful avoidance. Ss that falled to meet the criterion by the 80 th session were discarded. Thus, two Ss from the P group were discarded.

After meeting the acquisition criterion, each $\mathrm{S}$ was rested for 30 days before retention testing was begun. During retention testing, Ss were run under the same conditions as during the acquisition phase (except for the omission of drug injections) until the same criterion-seven consecutive sessions at above $65 \%$ successful avoidance-was met. Ss that falled to meet this criterion by the 60th session were discontinued. Two Ss from the MgPe group and one S from the d-a group falled to meet the relearning criterion within the 60 sessions.

Results

Both drug groups met the acquisition criterion significantly faster than the $P$ group ( $p<.05$, MannWhitney U), but the MgPe group did not differ significantly from the d-a group (Table 1). However, the two drug groups differed significantly on another

Table 1 Number of days to reach avoidance criterion (seven consecutive sessions at $65 \%$ avoidance) by the three groups during acquisition and rekearning.

\begin{tabular}{lcccccccc}
\hline & \multicolumn{2}{c}{ MgPe } & \multicolumn{3}{c}{ d-amphet. } & \multicolumn{3}{c}{ placebo } \\
& Acquis. & Relearn. & \multicolumn{3}{c}{ Acquis. } & Relearn. & \multicolumn{3}{c}{ Acquis. Relearn. } \\
S1 & 7 & $60^{* *}$ & S7 & 8 & $60^{* *}$ & S13 & 11 & 14 \\
S2 & 8 & 7 & S8 & 10 & 13 & S14 & 55 & 7 \\
S3 & 8 & 7 & S9 & 10 & 13 & S15 & 55 & 7 \\
S4 & 9 & 7 & S10 & 15 & 7 & S16 & 59 & 8 \\
S5 & 10 & 7 & S11 & 22 & 24 & S17 & $80^{*}$ & \\
S6 & 27 & $60^{* *}$ & S12 & 26 & 7 & S18 & $80^{*}$ & \\
\hline
\end{tabular}

These $S$ were discarded since they failed to meet the acquisition criterion.

"*These $S s$ failed to releam during 60 releaming sessions, and were discontinued. 
measure-number of intertrial responses ("extra" responses, 1.e., those ineffective responses made in the absence of the warning signal) during the seven days of criterion performance. The MgPe group had a downward trend in these extra responses, which differed significantly from the upward trend of the d-a group (Drugs by Days interaction: $\mathrm{p}<.005, F$ trend test).

During relearning, the $\mathbf{P}$ group did not differ significantly from either of the drug groups, nor did the two drug groups differ significantly from each other, either on the measure of days to criterion (Table 1) or on intertrial responding during the seven criterion days. Discussion

The results on the acquisition phase of the experiment agree with those of Plotnikoff: The MgPe group, compared to the $\mathbf{P}$ group, showed superior acquisition of avoidance performance. The $d-a$ group, however, was also superior to the $\mathbf{P}$ group. In addition, the $\mathrm{MgPe}$ group showed greater discrimination than did the d-a group in responding to the warning signal during the seven criterion days; the $\mathrm{d}-\mathrm{a}$ group, in contrast, showed no discrimination, and even increased extra responding in the absence of the warning signal.

Frey \& Polidora (1967) found that MgPe facilitated avoidance performance by interfering with the freezing reaction of rats to shock. This is similar to the effect of d-amphetamine reported by Krieckhaus, Mller, \& Zimmerman (1965). Beach \& Kimble (1967) found that MgPe increased spontaneous activity and ${ }_{2}$ in addition, sustained S'' (rats') responsivity to the sound of a buzzer (the CS used in Plotnikoff's and the present studies).

A more parsimonlous explanation of the "leamingenhancement effect" of MgPe would be to view the drug effects as improving performance in an avoidance situation by counteracting the effects of shock (by decreasing freezing behavior) and/or by increasing the rats' responsivity to changes in external stimulf, rather than by increasing general learning ability. Frank \& Filby (1967), using a food-rewarded tagk wherein the $S$ was required to emit a low response rate (without an external signal being presented), found MgPe to interfere with, rather than to facilitate, learning.

The present results on retention are inconclusive and puzzling. The MgPe Ss showed an all-or-none type of retention. The placebo Ss showed considerable savings in their relearning. This latter effect may be due to the significantly longer training which the placebo Ss re- quired in order to meet the aequisition criterion. Because of this factor favoring retention in this group, and because two of the six Ss in this group were discarded due to poor learning before the relearning phase, leaving a selected group, we cannot use this group as a baseline on which to evaluate the effects of MgPe on retention.

Comparing the MgPe group with the d-a group (these groups being approximately equal in length of acquisition training), there was no statistically significant difference. Thus, we have tentatively concluded that MgPe has no memory-enhancing effect on avoidance performance.

\section{References}

BEACH, G., \& KIMBLE, D. P. Activity and responsivity in rats after magnesium pemoline injections. Science, 1967, 155, 698-701.

FRANK, LUCILLE, \& FILBY, YASUKO. Magnesium pemoline: deleterious effect on learning a food-rewarded task. In preparation.

FREY, P. W., \& POLIDORA, V. J. Magnesium pemoline: effect on avoidance conditioning in rats. Science, 1967, 155, 1281-1282.

GLASKY, A. J., \& SIMON, L. N. Magnesium pemoline: enhancement of brain RNA polymerases. Science, 1966, 151, 702-703.

KRIECKHAUS, E. E., MILLER, N. E., \& ZIMMERMAN, P. Reduction of freezing behavior and improvement of shock avoidance by d-amphetamine. J. comp. physiol Psychol, 1965, 60, 36-40.

MORRIS, N. R., AGHAJANIAN, G. K., \& BLOOM, F. E. Magnesium pemoline: faikure to affect in vivo synthesis of brain RNA. Science, $1967,155,1125-1126$.

PLOTNIKOFF, N. Magnesium pemoline: enhancement of learning and memory of a conditioned avoidance response. Seience, 1966, 151, 703.704.

STEIN, H. H., \& YELLIN, T. O. Pemoline and magnesium hydroxide: lack of effect on RNA and protein synthesis. Science, 1967, 157, 96-97.

\section{Notes}

1. Now at Creedmoor Institute for Psychobiologic Studies, Station 60, Queens Village, New York.

2. Recent studies (Morris et al, 1967; and Stein \& Yellin, 1967), however, have failed to replicate these findings.

3. The drugs were prepared as follows:

(1) Magnesium pemoline: 2-imino-4keto-5-phenyloxozolidine (pemoline) was obtained from Aldrich Chemical Co., Milwaukee, Wis. The magnesium chelate was prepared from this by adding $\mathrm{MgSO}_{4}$ to the aqueous ethanolic solution of the compound at pH 11 (C. A. $601185 \mathrm{~d}$ (1964). The pulverized MgPe was suspended in a phosphate buffer ( $\mathrm{pH} 7.0$, $0.15 \mathrm{M}$ ) containing $1 \%$ Tween 80 for intraperitoneal injection. Note that the $40 \mathrm{mg} / \mathrm{kg}$ dose used in this study is twice the highest dose in the Plotnikoff, Beach, and Kimble, and Frey and Polidora studies.

(2) Placebo consisted of the same buffer-Tween 80 solution without $\mathrm{MgPe}$.

(3) d-amphetamine sulfate (Dextramine, Tech. Biochemical $\mathrm{Co}_{\text {., Fort }}$ Worth, Texas) $(1 \mathrm{mg} / \mathrm{ml})$ discolved in physiological saline.

4. We thank J. Whitley for valuable technical assistance. 